\title{
Cuidado da criança com deficiência na Atenção Primária à Saúde
}

\author{
Thaís Giudice Schultz, Carolina Maria do Carmo Alonso \\ Departamento de Terapia Ocupacional, Universidade Federal do Rio de Janeiro - UFRJ, Rio de Janeiro, RJ, Brasil.
}

\begin{abstract}
Resumo: Objetivo: Este artigo é um relato de experiência que teve como objetivo apresentar as percepções sobre o cuidado da criança com deficiência no âmbito da Estratégia de Saúde da Família (ESF), evidenciando seus limites e potencialidades a partir da experiência de participação no PET-Saúde. Método: A fonte de dados utilizada foi o caderno de campo em que se registrou o acompanhamento do processo de cuidado oferecido às crianças com deficiência por equipes da ESF de um serviço de saúde da cidade do Rio de Janeiro, durante o período de um ano. Resultados: O resultado da análise do conteúdo dos registros elencou duas categorias temáticas que se constituíram como eixo para apreensão da problemática do cuidado da criança com deficiência no âmbito da experiência vivenciada: a coordenação da atenção em saúde e a orientação familiar e comunitária, como eixo do cuidado da criança com deficiência na ESF. Conclusão: Foi possível verificar que, apesar da fragilidade na observância dessas categorias, que se constituem princípios e fundamentos da ESF, esse campo configura-se um palco privilegiado no que se refere às práticas de cuidado à criança com deficiência.
\end{abstract}

Palavras-chave: Crianças com Deficiência, Atenção Primária à Saúde, Estratégia Saúde da Família.

\section{Care of children with disabilities in Primary Health Care}

\begin{abstract}
Objective: This article describes an experience report that aimed to present perceptions on the care of children with disabilities in the Family Health Strategy (FHS), showing its limits and potentials based on the experience of participation in the program 'PET-Saúde'. Method: Data were collected from field notes which recorded the monitoring of the care process offered to children with disabilities by the FHS teams. The study was conducted in a health facility in the city of Rio de Janeiro for one year. Results: Content analysis results listed the two main themes that composed the issues of concern for child care in this experience: the coordination of health care and the family and community orientation as the core for child care in the FHS. Conclusion: Despite the weakness in compliance with these categories, which are principles and fundamentals of the FHS, this is a privileged space with regard to care practices for children with disabilities.
\end{abstract}

Keywords: Children with Disabilities, Primary Health Care, Family Health Strategy.

Autor para correspondência: Thais Giudices Shultz, Faculdade de Medicina, Universidade Federal do Rio de Janeiro, Rua Prof. Rodolpho Paulo Rocco, s/n, Prédio do CCS, Bloco K, Sala k49, Cidade Universitária, Ilha do Fundão, CEP 21910-590, Rio de Janeiro, RJ, Brasil, e-mail: thais.giudices@gmail.com 


\section{Introdução}

O cuidado à pessoa com deficiência, no Brasil, se constituiu, de forma hegemônica, por serviços de caráter assistencialista e hospitalocêntrico. Caracterizam-se por grandes centros especializados, que possuem, como objetivo final, a reabilitaçáo da função física dos indivíduos. Assim, as demais dificuldades enfrentadas pela pessoa com deficiência, como a limitação em seu desempenho funcional e em sua participação social, são consideradas fatores decorrentes da alteração biopatológica (ALMEIDA, 1997, 2000; OLIVER et al., 2001).

Tal configuração acarreta um hiato entre as açôes de cuidado previstas pelos centros de reabilitação especializados e a real necessidade da grande parcela da população com deficiência (ALONSO, 2009). A falta de acesso aos serviços de saúde e de reabilitaçáo mostra-se como um dos principais problemas enfrentados por essa população, apontando para a fragilidade do sistema de saúde e a precariedade das condições de vida impostas, principalmente à população de baixa renda (AOKI, 2009).

Esse processo decorre, principalmente, do fato de que o serviço de reabilitaçáo localiza-se em áreas centrais, gerando uma barreira no acesso dessa população pelas dificuldades objetivas de deslocamento e acessibilidade encontradas no decorrer do trajeto, além de baixa cobertura assistencial frente a essa demanda de cuidado (NALLIN, 1992; OLIVER et al., 1999; ALMEIDA; CAMPOS, 2002).

Essa dificuldade de assistência à população com deficiência era bem mais evidente antes do advento do Sistema Único de Saúde (SUS). Após a criação desse Sistema, em 1988, o cenário composto pelas pessoas com deficiência passou a receber maior atenção, pautando a agenda dos serviços públicos de saúde, na busca de superação de um quadro de histórico de exclusão (MALFITANO; FERREIRA, 2011). Ressalta-se, entretanto, que essa demanda de cuidado ainda náo foi completamente sanada, conforme afirmam os autores citados no parágrafo anterior.

Contudo, com base na universalidade, princípio orientador do SUS, todos os grupos sociais passaram a ter direito de acesso a saúde, possibilitando a criação de novos equipamentos sociais, para atender às demandas advindas da incorporação dessa população (LEÃO, 2000 apud MALFITANO; FERREIRA, 2011).

Logo, frente às mudanças ocorridas no cenário dos serviços de saúde, incluindo o campo da atenção à saúde da pessoa com deficiência na Atenção Primária à Saúde (APS), demandou-se um novo perfil dos profissionais de saúde. Nesse cenário, a Política Nacional de Saúde da Pessoa com Deficiência, instituída em 2002, reconhece a necessidade de atender às complexas questóes que envolvem a atenção à saúde das pessoas com deficiência no Brasil, tais como prevenção de agravos, proteção e reabilitação dessa população (BRASIL, 2010b). Em 2012, a Portaria n. 793 institui a rede de cuidados à pessoa com deficiência no SUS, por meio da criação, ampliação e articulação de pontos de atenção dirigidos a esse público (BRASIL, 2012b).

Frente a esse palco de transiçôes, emerge o Programa de Educação pelo Trabalho para a Saúde (PET-saúde), que é uma estratégia que visa a modificar a formação dos profissionais de saúde por meio da integraçáo ensino-serviço-comunidade (FERRAZ, 2012).

O projeto intitulado "Atenção à Saúde da Pessoa com Deficiência na Estratégia de Saúde da Família: discutindo necessidade e novas possibilidades de cuidado" se localizou no âmbito da proposta do PET-Saúde e teve como objetivo promover a integração ensino, serviço e pesquisa no campo das práticas territoriais de cuidado à saúde das pessoas com deficiência, por meio da análise das açóes desenvolvidas pelos profissionais das equipes de saúde da família e do Núcleo de Apoio a Saúde da Família (NASF), na cidade do Rio de Janeiro (ALONSO, 2012).

Além disso, o projeto possibilitou a inserção de alunos dos cursos de Terapia Ocupacional (TO) e de outras profissóes de saúde, que atuavam no cuidado à saúde da pessoa com deficiência em Serviços da ESF-NASF e/ou de Reabilitaçáo Baseada na Comunidade e de atenção secundária, ressalvando a condição necessária de integrarem a rede SUS, conforme Alonso (2012).

Nesse contexto, a partir da participação de uma aluna acadêmica de TO no referido projeto, foi possível uma familiarização com o trabalhar das equipes da Estratégia Saúde da Família (ESF) e do NASF, e, ainda, conhecer o cenário inerente à população com deficiência do território de abrangência da Unidade Básica de Saúde (UBS) em que ocorreu o projeto.

Assim, por meio de uma maior aproximação com a política do SUS, no âmbito da atenção básica, seus desdobramentos na prática, e uma visão mais contextualizada do processo de cuidado voltado à população referida, um público em específico foi o objeto deste artigo: as crianças com deficiência. Dessa forma, esta pesquisa parte do pressuposto de que a população infantil, quando inserida em grupos 
populacionais específicos, como a deficiência, estará submetida a alguma forma de exclusão social.

Tal consideração vai ao encontro do relatório da Situação Mundial da Infância, divulgado em 2013, pelo Fundo das Naçóes Unidas para a Infância (UNICEF), que aponta que as crianças que vivem na pobreza e possuem deficiência estão entre aquelas com menor probabilidade de usufruir de educação e de cuidados com a saúde, sendo, inclusive, mais vulneráveis à violência e aos abusos (FUNDO..., 2013).

Assim, o objetivo deste artigo é apresentar as percepçóes sobre o cuidado da criança com deficiência, no âmbito da ESF, evidenciando seus limites e potencialidades observados durante o período de participação no PET-Saúde.

A fim de oferecer ao leitor um embasamento do contexto desta pesquisa, assim como uma aproximação dos conceitos que serão problematizados e discutidos, alguns temas que atravessam este trabalho serão apresentados nos subitens a seguir.

\subsection{Fundamentos e diretrizes da Atenção Básica}

A Atenção Básica configura-se como porta preferencial de entrada para o SUS e como centro de comunicação da Rede de Atenção à Saúde. Orienta-se pelos princípios da universalidade, da acessibilidade, do vínculo, da continuidade do cuidado, da integralidade da atenção, da responsabilização, da humanização, da equidade e da participação social. Segundo o Ministério da Saúde, são fundamentos e diretrizes deste nível de atenção (BRASIL, 2012a):

i) Ter território adstrito, de forma a facilitar o planejamento e o desenvolvimento de ações setoriais e intersetoriais com impacto na situação da comunidade que constitui esse território, de acordo com seus condicionantes e determinantes de saúde;

ii) Possibilitar o acesso universal e contínuo dos usuários aos serviços de saúde de qualidade, promovendo o acolhimento, a vinculação e corresponsabilização pela atenção às suas necessidades de saúde;

iii) Garantir a continuidade das açôes de saúde e a continuidade do cuidado através da construção de vínculo e responsabilização entre usuários e profissionais ao longo do tempo, evitando a perda de referências e mantendo a coordenaçáo do cuidado; iv) Coordenar a integralidade em seus vários aspectos, através da integração de ações programáticas, da articulação de ações de promoção à saúde, prevenção de agravos, vigilância à saúde, tratamento e reabilitação, trabalhando de forma interdisciplinar e em equipe;

v) Estimular a participação dos usuários como forma de ampliar sua autonomia e capacidade na construçáo do seu cuidado, a partir de lógicas mais centradas no usuário e no exercício do controle social.

No Brasil, o modelo preferencial de operação da Atenção Básica é a Estratégia Saúde da Família, que tem suas ações norteadas pelo

[...] cuidado familiar ampliado, que se efetiva por meio do conhecimento da estrutura e da funcionalidade das famílias, com o intuito de que as suas intervençôes influenciem os processos de saúde-doença dos indivíduos, das famílias e da própria comunidade [...] (BRASIL, 2006, p. 26).

Destaca-se, ainda, como eixo de ação dos profissionais das equipes de Saúde da Família, o desenvolvimento da intersetorialidades, que opera por meio de parcerias entre equipamentos que potencializem as redes de suporte sociais das famílias e comunidades atendidas pelas equipes de Saúde da Família (BRASIL, 2006).

\subsection{O cuidado da criança com deficiência na ESF}

Adentrando-se ao núcleo da criança com deficiência, a UNICEF considera que pelo menos $10 \%$ das crianças no mundo nascem ou adquirem algum tipo de deficiência física, mental ou sensorial, repercutindo de forma negativa no desenvolvimento neuropsicomotor.

Por outro lado, cerca de 70 a $80 \%$ das sequelas podem ser evitadas ou minimizadas através de condutas e procedimentos simples de baixo custo e possível operacionalização (UNICEF apud BRASIL, 2004, p. 33).

Em relação ao Brasil, no escopo de ação da ESF, o monitoramento permanente de ocorrências de deficiências e incapacidades nas crianças, assim como a análise da prevalência e tendência, constitui uma meta a ser alcançada pelos gestores de saúde, objetivando o planejamento de serviços e adoção de medidas preventivas desenvolvidas pelo SUS (BRASIL, 2004). 
Podem-se apontar dois focos principais que direcionam as ações em prevenção desenvolvidas no SUS, envolvendo toda a rede de atenção: as realizadas para intervir nos eventos que causam as deficiências e as realizadas para evitar a progressão de uma deficiência já instalada.

No primeiro foco, entre as principais açôes, estão: acompanhamento do pré-natal, especialmente das gestantes de risco, e do pós-natal; acompanhamento do crescimento e desenvolvimento infantil; programas de vacinação contra poliomielite, sarampo e rubéola, e acesso a exames para descobrir doenças genéticas que causam deficiência (BRASIL, 2010a).

No segundo foco, para evitar a progressão de uma deficiência já existente, as pessoas devem ser acompanhadas pelas Equipes de Saúde da Família (EqSF) e, quando necessário, ser encaminhadas para os serviços de reabilitação do SUS (BRASIL, 2010a).

Assim, a partir do cadastro da criança, a EqSF deve prestar atençáo integral e multiprofissional, possibilitando a detecçáo dos problemas em tempo oportuno para o desenvolvimento de açóes de diagnóstico e intervenção precoce, de habilitação e reabilitaçáo, promoção de saúde e prevençáo de impedimento físico, mental ou sensorial e de agravos secundários, minimizando as consequências da deficiência (BRASIL, 2004).

Nessa configuração, o dispositivo da visita domiciliar ou o atendimento continuado da criança assumem papel central no cuidado. A equipe de saúde deve estar atenta a alguns sinais de alerta, como: atraso nas aquisiçóes neuropsicomotoras, comportamentos estereotipados e repetitivos, apatia frente a estímulos do ambiente, dificuldade em fixar visualmente o rosto da máe e objetos, e ausência de resposta a estímulos sonoros. Na presença de qualquer alteraçâo do desenvolvimento psicomotor, a criança deve ser encaminhada à UBS para avaliação com pediatra e equipes de reabilitação, se necessário (BRASIL, 2004).

$\mathrm{O}$ cuidado integral à criança com deficiência e a promoção da sua qualidade de vida pressupóe reabilitá-la na sua capacidade funcional e desempenho humano, além de proteger sua saúde para que possa desempenhar o seu papel em todas as esferas da vida social. Esse cuidado inclui o diagnóstico, o tratamento, os encaminhamentos para serviços de reabilitação, os medicamentos, a assistência odontológica, as ajudas técnicas e a nutrição adequada; o fornecimento de órteses, próteses, bolsas pediátricas de colostomias, medicamentos e leites especiais obedece ao fluxo local de assistência (BRASIL, 2004).

Também são de competência da atenção básica em saúde a indicação e a orientação para recursos assistenciais e benefícios disponíveis, como o auxílio-doença e outros programas, e políticas públicas para a garantia dos direitos, como o das crianças com deficiência frequentarem o ensino regular (BRASIL, 2010a).

\subsection{A abordagem no cuidado da criança com deficiência}

Aumentar a autoconfiança, a capacidade e a autonomia de indivíduos e grupos sociais, seja nas relaçóes interpessoais, seja nas institucionais, deve ser o objetivo central das boas práticas de reabilitação da saúde. Isso tem sido chamado de empoderamento. Seu significado é fundamental e traduz o desenvolvimento de potencialidades e o aumento de informação, da percepção e da participação real e simbólica dos pacientes, que assim passam a ser sujeitos e não meramente objetos das açôes (BRASIL, 2010a).

Entretanto, verifica-se que o cuidado à criança com deficiência significa não só a adoção de medidas de caráter reabilitativo, já que essa população encontra diferentes formas de exclusão, dependendo do tipo de deficiência, do local onde moram e da cultura ou da classe social a que pertencem (FUNDO..., 2013). Essa interação do sujeito com diversos fatores da esfera biopsicossocial e cultural reflete diretamente na forma de cuidado que deve ser prestada a essa população. O seu atendimento clínico deve estruturar-se em açôes específicas e complementares, bem como deve envolver também outros atores, dentro da lógica de que a deficiência não é uma questáo exclusiva da saúde, mas também de outras políticas públicas (BRASIL, 2010a).

Assim, no âmbito da atenção básica, a abordagem de cuidado a essa criança deve ter como referencial a promoção da sua inclusão e participação social. Para tanto, é necessária a atuação integrada da equipe de saúde com a família, a comunidade e os equipamentos sociais disponíveis (BRASIL, 2004).

Dessa forma, o relato que aqui se apresenta parte do pressuposto de que todas as estratégias e iniciativas advindas do campo da APS, no cuidado à criança com deficiência, devem atuar como elemento propulsor do fomento e consolidação da sua participação social.

Analisada e observada a partir da definiçáo utilizada na Classificação Internacional de Funcionalidade, Incapacidade e Saúde (CIF), a participação social é entendida como o envolvimento em uma situaçáo de vida (ORGANIZAÇÃO..., 2003). A CIF descreve as diversas açóes e áreas da vida que fazem parte do que se chama de atividade e participação, sendo estas: 
aprendizagem e aplicação de conhecimentos; tarefas e demandas gerais; comunicação; mobilidade; cuidado pessoal; vida doméstica; interaçôes e relacionamentos interpessoais, e experiência comunitária, social e cívica.

Destarte, verifica-se que as ações de assistência à saúde, destinadas às pessoas com deficiência, devem ser inseridas num sistema amplo que abrangerá a implementação de programas de reabilitação, envolvendo a família e a comunidade, em que a ESF tem papel fundamental (BRASIL, 2010a).

\section{Método}

O presente artigo trata de um relato de experiência que usou, como fonte de dados, registros do caderno de campo de uma aluna bolsista do PET-Saúde, participante do projeto do curso de Terapia Ocupacional, da UFRJ, intitulado "Atenção à Saúde da Pessoa com Deficiência na Estratégia de Saúde da Família: discutindo necessidades e novas possibilidades de cuidado".

As informaçôes utilizadas para composição deste trabalho foram coletadas de março de 2013 até março de 2014 e consistem no registro do acompanhamento do processo de cuidado oferecido às crianças com deficiência por equipes da estratégia saúde da família. Os registros foram construídos a partir do diário de campo, que contava com as principais impressóes e observações semanais acerca do cuidado oferecido à criança e à sua família.

A par disso, o instrumento de coleta e armazenamento das descriçôes e reflexóes foi o diário de campo, que registrou suas vivências no território, abrangendo a conversa com a família da criança, o contato com o espaço e o local que lhes eram próprios, e a abordagem do profissional de saúde e do agente comunitário, permitindo compreender a dinâmica e a caracterizaçáo do objeto de estudo.

Dessa forma, por meio do exercício de observação e recordação, foram construídos os registros que direcionaram esta pesquisa e buscou-se que fossem os mais amplos possíveis, a partir de anotaçóes minuciosas da autora acerca dos afetos, sentimentos e outras percepçóes. "Essas percepçôes foram projetadas nas notas que, por sua vez, se projetaram na pesquisadora, retroalimentando o processo de pesquisa e reflexão [...." (GALHEGO, 2002 apud AOKI, 2009, p. 19).

A partir da maior incidência de percepçôes observadas, estabeleceram-se as categorias temáticas, servindo de palco para a discussão do tema central desta pesquisa. Essas categorias foram, portanto, definidas a partir da apuração dos registros efetuados durante a pesquisa, tratando-se, portanto, do modelo aberto de categorias, táo comuns em estudos exploratórios (LAVILLE; DIONNE, 1999).

Os procedimentos para análise dos dados colhidos para esta pesquisa basearam-se em preceitos de Franco (2004) e seguiram as seguintes etapas: pré-análise - leitura minuciosa do material visando a selecionar e organizar os conteúdos encontrados; exploração do material - busca ativa de conteúdos que respondessem aos objetivos estabelecidos, conduzindo à elaboraçáo de categorias temáticas; tratamento dos resultados - reordenação dos dados obtidos nas etapas anteriores da análise e interpretação dos resultados de forma integrada à literatura acadêmica.

Esta pesquisa consiste em um material resultante de intervenção, em que se observaram os seguintes aspectos éticos: o projeto que serviu de base para construção do relato de experiência foi autorizado formalmente pelo gestor municipal, bem como pelo gestor do serviço; os resultados foram validados com os membros das equipes de saúde da família que acompanharam a experiência relatada; para evitar constrangimentos dos usuários durante as visitas domiciliares, as interaçôes não foram gravadas, sendo registradas posteriormente em diários de campo; nomes e/ou outras informaçóes que, de alguma forma, pudessem identificar usuários ou trabalhadores das equipes de saúde da família foram omitidos.

\section{Resultados e Discussão}

O resultado da análise dos registros elencou duas categorias temáticas, apresentadas a seguir, que se constituíram como eixo para apreensão da problemática do cuidado da criança com deficiência no âmbito da experiência vivenciada pela aluna pesquisadora.

\subsection{Coordenação do cuidado da criança com deficiência}

Sobre essa categoria temática, o conteúdo dos registros realizados apontou para o fato de que o cuidado da criança com deficiência ainda está fortemente vinculado aos serviços especializados que, por sua vez, têm uma integração frágil com a ESF.

A esse respeito, verificou-se, por meio do acompanhamento dos casos, que os serviços especializados desconhecem a condição financeira, a qualidade da moradia e as barreiras físicas e sociais próprias do território em que essa criança se insere. Tal desconhecimento gera um hiato entre as açóes de reabilitação empreendidas e o contexto em que a vida dessas crianças se constrói, comprometendo a oferta de uma atenção integral a essa população. 
Durante a participação no projeto, foi verificado, a partir do relato da família, que, em algumas situações, as orientações prestadas pelos profissionais dos serviços especializados náo eram compatíveis com a realidade das famílias atendidas.

Como exemplo, toma-se o episódio durante uma visita à casa de uma mãe de uma criança com deficiência, que foi orientada pelo profissional do centro de reabilitação que colocasse seu menino no chão para que tivesse um ambiente maior para brincar e explorar, experimentando novas posturas. Entretanto, considerando-se as condiçôes de moradia dessa família, vê-se, claramente, que a estratégia não podia ser operacionalizada conforme as orientaçóes prescritas. Como a própria mãe relatou: "Como colocar meu menino nesse chão?”, enquanto direcionava o olhar para o piso inacabado e totalmente coberto por terra.

Varela e Oliver (2013) reforçam essa observação e consideram que a indicação, por exemplo, de uma cadeira de rodas, deve ir além das especificaçôes do produto de ordem mecânico-instrumental. É necessário considerar o contexto político, social, cultural e econômico do sujeito para o qual se prescreve o dispositivo, garantindo que o recurso esteja, então, em consonância com o contexto de sua vida.

Assim, a indicação da tecnologia assistiva, bem como a orientaçấo de qualquer estratégia, não deve seguir uma racionalidade exclusivamente técnica ou tecnológica. Faz-se necessário verificar se tais prescriçôes consideram a singularidade dos usuários, garantindo a integraçáo dos recursos, serviços e orientaçóes advindos dos serviços especializados, à vida cotidiana das crianças e sua família (CAMPOS, 2011 apud VARELA; OLIVER, 2013).

A partir dessas observaçóes, no âmbito da experiência vivenciada, verificou-se que, apesar de as equipes de saúde da família considerarem importantes a discussão e o compartilhamento desses casos com os serviços especializados, essas equipes possuem pouca clareza das ferramentas para tecer essa articulação e efetivar a coordenação do cuidado das crianças com deficiência.

Verifica-se que as equipes de saúde da família são responsáveis por organizar o fluxo dos usuários entre os pontos da Rede de Atenção à Saúde (RAS), responsabilizando-se pelo cuidado dos usuários através dos diferentes níveis assistenciais. Assim, deve-se acionar a Rede de Cuidados à Saúde da Pessoa com Deficiência, visando a garantir a articulação e a integração dos pontos de atenção das redes de saúde do território, qualificando o cuidado oferecido ao usuário (BRASIL, 2013).
Cabe entender que a coordenação entre níveis assistenciais pode ser definida como a articulação entre os diversos serviços e ações de saúde relacionada à determinada intervenção, de forma que, independentemente do local onde sejam prestados, estejam sincronizados e voltados ao alcance de um objetivo comum (NÚNEZ, 2006 apud ALMEIDA et al., 2010).

Nesse sentido, reflete-se na existência de uma rede integrada - da Atenção Primária à Saúde aos prestadores de maior densidade tecnológica - , de modo que distintas intervençóes do cuidado sejam percebidas e experimentadas pelo usuário de forma contínua, adequada às suas necessidades de atenção em saúde e compatível com as suas expectativas pessoais (BOERMA, 2007 apud ALMEIDA et al., 2010).

\subsection{Construção do cuidado pautado pela orientação comunitária e familiar}

A ESF apresenta, como um de seus fundamentos, a promoção de intervençôes com orientação comunitária e familiar, ampliando o escopo dos projetos terapêuticos. No entanto, os registros da vivência da aluna no acompanhamento das equipes de saúde da família evidenciaram que seus profissionais ainda têm açóes marcadas pelo atendimento de sintomas e de doenças. A constatação da pesquisadora vai ao encontro dos apontamentos de Teixeira (2001, p. 238), conforme se verifica:

A dupla de técnicos (médico/enfermeiros) adotados pelo Ministério da Saúde realiza uma assistência voltada, a princípio, para os aspectos epidemiológicos, ou seja, de reduçáo de morbi mortalidade, nas faixas etárias e situaçôes de 'risco' determinadas, mas que ainda não consegue, em seu todo, visualizar seus usuários como sujeitos sociais, pois não foi preparada acadêmica e nem socialmente para tal. Podemos afirmar que, no momento, em sua maioria, tal modelo de assistência tende a reproduzir a prática médica que trata de patologias e não de cidadáos.

Tal quadro apresentou seus reflexos nos casos de crianças com deficiência, acompanhadas durante a experiência da aluna no projeto, pela constatação das dificuldades das equipes em incorporar, nos projetos terapêuticos, açôes que potencializassem o aumento da participação social desse grupo populacional.

Verificou-se que, muitas vezes, as equipes tiveram dificuldades em tecer projetos terapêuticos que transcendessem as problemáticas orgânicas 
nos quais a questão da circulação no território, a inclusão escolar ou mesmo a abordagem familiar fossem adotadas como eixo no cuidado dos casos identificados.

Esse fato se explica devido à lógica do modelo biomédico ainda muito arraigado nos profissionais que dirigem a escuta para o biológico, para a queixa da doença, desvalorizando a escuta, o diálogo, a palavra. Excluindo essas ferramentas de cuidado, anula-se a condição de sujeito, de humano e de singular (ERDMANN; SOUSA, 2009).

Tal problemática nos conduz a pensar na iminente necessidade de uma formação acadêmica direcionada à construção de um olhar voltado à integralidade do sujeito, atendendo às suas questóes psicossociais. Dessa forma, cabe ao profissional da saúde compreender que a construção do cuidado do seu usuário pode acontecer na Unidade Básica de Saúde, mas também em dispositivos territoriais (salóes comunitários, escolas, creches, praças etc.) e em outros espaços que comportem a ação planejada (BRASIL, 2012a).

Para melhor apreensão dessa problemática, serão discutidas, a seguir, as questôes da abordagem familiar e comunitária, disparadas a partir das vivências da aluna e articuladas ao referencial teórico concernente ao tema.

\subsubsection{Abordagem familiar}

A família é a primeira rede de apoio da criança e, por isso, os projetos terapêuticos singulares devem abranger toda a família, oferecendo acolhimento e cuidado frente a suas demandas. Contudo, a partir das vivências no acompanhamento das equipes, verificou-se que a abordagem individual se sobrepóe ao cuidado da família. A fim de ilustrar esse apontamento, considera-se o caso de uma criança acompanhada no percurso do projeto, que apresentava um quadro clínico de paralisia cerebral associado a episódios frequentes de convulsão. Não obstante os esforços empreendidos para atender às inúmeras demandas da criança, sua mãe apresentava visível dificuldade em cumprir os horários dos atendimentos estabelecidos pelos serviços de saúde, bem como as orientaçóes sobre o cuidado com seu filho.

Apesar da necessidade de acolhimento familiar, verificou-se que, em alguns casos, o direcionamento da equipe de saúde consistia na patologia e nos sinais e sintomas decorrentes. Assim, a discussão do projeto terapêutico acabava por ficar centrada na provisão de medicamentos necessários para o controle das crises e as outras demandas da criança, que se manifestavam no âmbito familiar e social, por exemplo, figuravam desvanecidas perante o plano de cuidado dos profissionais.

Diante do que se pôde observar e de acordo com a Política Nacional de Atenção Básica (PNAB), verifica-se que as equipes de saúde da APS devem colocar em ação o atributo da centralização na família, que se funda no conhecimento de cada unidade familiar para além de seus problemas de saúde. Nessa direção, o contexto familiar passa a fazer parte da avaliação das necessidades de saúde no intuito de atender ao desafio da atenção integral (STARFIELD, 2002 apud CALDEIRA, 2009).

Nos casos de atendimento de crianças com deficiência, a necessidade de fortalecer a abordagem familiar se dá de forma premente, visto que a participação social dessa população é potencializada quando a sua família é incluída na pauta de cuidado.

Contudo, para adentrar no campo das relações sociais do sujeito, faz-se necessário partir da família e alçar o olhar para o território onde essas pessoas vivem. Essa temática será explorada no tópico a seguir.

\subsubsection{Abordagem comunitária}

Os registros dos acompanhamentos feitos pela pesquisadora indicaram que a abordagem comunitária é operada de forma frágil, no universo objeto de estudo.

Diante disso, verificou-se que há dificuldade das equipes em ampliar o repertório das suas açóes integrando, nos projetos terapêuticos, estratégias de cuidado importantes para aumento da participação social, sobretudo das pessoas com deficiência, como, por exemplo, inclusão escolar, transporte adaptado, acessibilidade dos espaços comunitários.

Por outro lado, a experiência de conhecer o território de abrangência da ESF durante as visitas domiciliares permitiu verificar a escassez de atividades dispostas na comunidade, tais como: oficinas de artesanato, teatro, dança, música, grupos de convivência, centros vocacionais e esportivos, que pudessem enriquecer o cotidiano dos seus moradores.

Assim, constrói-se a hipótese de que a precariedade das atividades e de dispositivos socioculturais alocados no território das comunidades estudadas oferece impacto a todos que vivem imersos nesse cenário, devido à maior vulnerabilidade da rede de suporte social direcionada a esses indivíduos.

Entretanto, no caso das crianças com deficiência, esse panorama reforça o cenário de isolamento social, de empobrecimento do fazer e de fragilidade das trocas sociais recorrente no cotidiano dessa população, que 
já apresenta dificuldade de inserção em instituiçóes basilares como a escola e os espaços de lazer.

Tomando-se como exemplo o caso anteriormente mencionado, observou-se que o circuito territorial da criança consistia, exclusivamente, no trajeto do seu domicílio até o serviço de reabilitação. Tal fato revela o comprometimento na sua participaçáo social, o que se reflete em limitaçôes no desempenho de atividades e na precarização da sua rede de suporte social.

A partir das questóes mencionadas, pode-se atentar para a iminente importância de considerar intervençōes e abordagens que transcendam a oferta de procedimentos centrados na doença/deficiência, e que sejam direcionadas à família, abrangendo também a comunidade.

De posse dessas informações, pode-se compreender a importância de outro atributo da APS: a orientação para a comunidade. Esse atributo desenvolve-se a partir da constatação de que todas as necessidades relacionadas à saúde dos pacientes ocorrem em um contexto social e que a identificação dessas necessidades, frequentemente, requer o conhecimento desse aspecto (STARFIELD, 2002 apud CALDEIRA, 2009).

Diante deste quadro, Oliver et al. (2003) chamam atenção para o fato de que as desvantagens vividas pelas pessoas com deficiências, principalmente aquelas que habitam áreas onde as condições e a qualidade de vida são precárias, costumam ser mais limitadoras para a pessoa do que para suas deficiências. Percebe-se, então, que há situações que levam pessoas com o mesmo tipo de incapacidade funcional a ter diferentes níveis de restrição no desempenho de suas atividades diárias, condicionadas por seu nível socioeconômico e cultural.

Assim, considera-se que o enfoque territorial e comunitário pode trazer ao processo de cuidado às crianças com deficiência contribuiçóes importantes ao potencializar a interaçáo do sujeito com o seu meio, diagnosticando e enfrentando as barreiras no intuito de fomentar a participação social de todos: criança, família, comunidade.

\section{Apontamentos finais}

O objetivo deste artigo foi apresentar e discutir as percepçôes sobre o cuidado da criança com deficiência no âmbito da ESF, evidenciando seus limites e potencialidades. Desse modo, a partir das vivências oferecidas por meio do PET-Saúde, foi possível observar um cenário em que as açôes dirigidas às crianças com deficiência na APS mostravam-se frágeis frente à aplicação de alguns de seus princípios e fundamentos, como a coordenaçáo do cuidado e a construção de uma atenção integral calcada na orientação familiar e comunitária.

Além disso, verificou-se que as limitaçôes encontradas por esse público transcendem os impositivos da própria deficiência, situando-se na dificuldade de acesso aos serviços de saúde, no isolamento em domicílio, na precariedade das redes sociais e na dificuldade de inserção nos dispositivos territoriais. Dessa forma, a ESF fulgura como um campo fértil para o desenvolvimento de práticas de atenção à saúde da pessoa com deficiência, mormente por permitir uma abordagem voltada para a construção da participação social.

Assim, apesar das limitaçóes que hoje podem ser encontradas na ESF na atenção à saúde da criança com deficiência, reiteram-se as extensas possibilidades de ação nesse campo, por meio do fomento de estratégias pautadas pela orientação familiar e comunitária. De outro lado, as análises apresentadas neste relato apontam para a necessidade de aprofundar a reflexão sobre as possibilidades e os aspectos limitantes da prática, bem como de direcionar o olhar para o contexto familiar e sociocultural no cuidado da criança com deficiência.

\section{Agradecimentos}

As autoras agradecem à Rosana Tibúrcio pela revisão do texto.

\section{Referências}

ALMEIDA, M. C. O cotidiano da pessoa deficiente: reflexo e reflexóes sobre reabilitação. Revista de Terapia Ocupacional da Universidade de São Paulo, São Paulo, v. 8, n. 2/3, p. 81-86, 1997.

ALMEIDA, M. C. Saúde e reabilitação de pessoas com deficiência: políticas e modelos assistenciais. 2000. 253 f. Tese (Doutorado em Saúde Coletiva) - Universidade Estadual de Campinas, Campinas, 2000.

ALMEIDA, M. C.; CAMPOS, G. W. S. Políticas e modelos assistenciais em saúde e reabilitação das pessoas portadoras de deficiência no Brasil: análise de proposições desenvolvidas nas duas últimas décadas. Revista de Terapia Ocupacional da Universidade de São Paulo, São Paulo, v. 13, n. 3, p. 118-26, 2002.

ALMEIDA, P. F. et al. Desafios à coordenação dos cuidados em saúde: estratégias de integração entre níveis assistenciais em grandes centros urbanos. Cadernos de Saúde Pública, Rio de Janeiro, v. 26, n. 2, p. 286-298, 2010.

ALONSO, C. M. C. Atenção à saúde da pessoa com deficiência na estratégia Saúde da Família: discutindo necessidades e novas possibilidades de cuidado. Rio de Janeiro: UFRJ, 2012. Projeto de Pesquisa.

ALONSO, C. M. C. O trabalho e o trabalhar de uma equipe de reabilitação no Programa Saúde da Família do 
município de São Paulo. 2009. 98 f. Dissertação (Mestrado em Ciências) - Universidade de São Paulo, São Paulo, 2009.

AOKI, M. Reabilitação com ênfase no território: demandas de pessoas com deficiência e a promoção da participação comunitária. 2009. 182 f. Dissertação (Mestrado em Ciências) - Universidade de São Paulo, São Paulo, 2009.

BRASIL. Ministério da Saúde. Secretaria de Atenção à Saúde. Departamento de Açóes Programáticas Estratégicas. Agenda de compromissos para a saúde integral da criança e redução da mortalidade infantil. Brasília, 2004.

BRASIL. Ministério da Saúde. Secretaria de Atenção à Saúde. Departamento de Atenção Básica. Política Nacional de Atenção Básica. Brasília, 2006.

BRASIL. Ministério da Saúde. Diretrizes do NASF: Núcleos de Apoio a Saúde da Família. Brasília, 2010a.

BRASIL. Ministério da Saúde. Secretaria de Atenção à Saúde. Departamento de Açóes Programáticas Estratégicas. Politica Nacional de Saúde da Pessoa com Deficiência. Brasília, 2010b.

BRASIL. Ministério da Saúde. Secretaria de Atenção à Saúde. Departamento de Atenção Básica. Política Nacional de Atenção Básica. Brasília, 2012a.

BRASIL. Portaria no 793, de 24 de abril de 2012. Institui a Rede de Cuidados à Pessoa com Deficiência no âmbito do Sistema Único de Saúde. Diário Oficial [da] República Federativa do Brasil, Brasília, DF, 25 abr. 2012b.

BRASIL. Ministério da Saúde. Secretaria de Atenção à Saúde. Conheça a rede de cuidados à pessoa com deficiência. Brasília, 2013.

CALDEIRA, V. A. Prática de terapia ocupacional em unidade básica de saúde na atenção às pessoas com deficiência. 2009. 170 f. Dissertação (Mestrado em Ciências) - Universidade de São Paulo, São Paulo, 2009.

ERDMANN, A. L.; SOUSA, F. G. M. Cuidando da criança na Atenção Básica de Saúde: atitudes dos profissionais da saúde. O Mundo da Saúde, São Paulo, v. 33, n. 2, p. 150-160, 2009.

FERRAZ, L. O PET-Saúde e sua Interlocução com o Pró-Saúde a partir da pesquisa: o relato dessa experiência. Revista Brasileira de Educaçâo Médica, Rio de Janeiro, v. 36, n. 1, p. 166-171, 2012.
FRANCO, M. L. P. B. Análise de conteúdo. Brasília: Líber Livro, 2004.

FUNDO DAS NAÇÓES UNIDAS PARA A INFÂNCIA - UNICEF. Situação Mundial da Infância 2013: criança com deficiência. Brasília, 2013. Disponível em: <http://www.unicef.org/brazil/pt/media_25543.htm>. Acesso em: 20 abr. 2014

LAVILLE, C.; DIONE, J. A construção do saber: manual de metodologia da pesquisa em ciências humanas. Porto Alegre: Artmed, 1999

MALFITANO, A. P. S.; FERREIRA, A. P. Saúde pública e Terapia Ocupacional: apontamentos sobre relaçóes históricas e atuais. Revista de Terapia Ocupacional da Universidade de São Paulo, São Paulo, v. 22, n. 2, p. 102-109, 2011.

NALLIN, A. Reabilitação em instituição. Suas razôes e procedimentos: análise de representação no discurso. 1992. 282 f. Dissertação (Mestrado em Psicologia) Universidade de São Paulo, São Paulo, 1992.

OLIVER, F. C. et al. Reabilitação baseada na comunidade - discutindo estratégias de ação no contexto sociocultural. Revista de Terapia Ocupacional da Universidade de São Paulo, São Paulo, v. 10, n. 1, p. 1-10, 1999.

OLIVER, F. C. et al. Reabilitação com ênfase no território: Jardim D’Abril e Jardim Boa Vista, no município de São Paulo. Revista de Terapia Ocupacional da Universidade de São Paulo, São Paulo, v. 14, n. 3, p. 141-146, 2003.

OLIVER, F. C. et al. Reabilitação no território: construindo a participaçáo na vida social. Revista de Terapia Ocupacional da Universidade de São Paulo, São Paulo, v. 12 , n. $1 / 3$, p. $15-22,2001$

ORGANIZAÇÃO MUNDIAL DE SAÚDE - OMS. Classificação internacional de funcionalidade, incapacidade e saúde: classificação detalhada com definiçóes, inclusôes e exclusóes. Genebra, 2003. Disponível em: <http://arquivo.ese.ips.pt/ese/cursos/edespecial/CIFIS. pdf>. Acesso em: 19 abr. 2014

TEIXEIRA, M. J. O. O Programa Saúde da Família, o Serviço Social e o canto do rouxinol. In: BRAVO, M. I. S.; PEREIRA, P. A. P. (Org.). Politica social e democracia. São Paulo: Cortez, 2001. p. 235-254.

VARELA, R. C. B.; OLIVER, F. C. A utilização de Tecnologia Assistiva na vida cotidiana de crianças com deficiência. Ciência \& Saúde Coletiva, Rio de Janeiro, v. 18, n. 6, p. 1773-1784, 2013.

\section{Contribuição dos Autores}

Thaís Giudice Schultz - concepção, redação do texto e organização de fontes. Carolina Maria do Carmo Alonso - concepção e redaçáo do texto, organização de fontes e revisão final. Todos os autores aprovaram a versão final do texto.

\section{Fonte de Financiamento}

O projeto que baseou a experiência relatada no presente artigo foi financiado pelo Ministério da Saúde pelo Programa de Educação pelo Trabalho para a Saúde (PET-Saúde). 